\title{
Etomoxir-induced partial carnitine palmitoyltransferase-I (CPT-I) inhibition in vivo does not alter cardiac long-chain fatty acid uptake and oxidation rates
}

Citation for published version (APA):

Luiken, J. J. F. P., Niessen, H. E. C., Coort, S. L. M., Hoebers, N., Coumans, W. A., Schwenk, R. W., Bonen, A., \& Glatz, J. F. (2009). Etomoxir-induced partial carnitine palmitoyltransferase-I (CPT-I) inhibition in vivo does not alter cardiac long-chain fatty acid uptake and oxidation rates. Biochemical Journal, 419(2), 447-55. https://doi.org/10.1042/BJ20082159

Document status and date:

Published: 01/01/2009

DOI:

10.1042/BJ20082159

Document Version:

Publisher's PDF, also known as Version of record

Document license:

Taverne

Please check the document version of this publication:

- A submitted manuscript is the version of the article upon submission and before peer-review. There can be important differences between the submitted version and the official published version of record. People interested in the research are advised to contact the author for the final version of the publication, or visit the DOI to the publisher's website.

- The final author version and the galley proof are versions of the publication after peer review.

- The final published version features the final layout of the paper including the volume, issue and page numbers.

Link to publication

\footnotetext{
General rights rights.

- You may freely distribute the URL identifying the publication in the public portal. please follow below link for the End User Agreement:

www.umlib.nl/taverne-license

Take down policy

If you believe that this document breaches copyright please contact us at:

repository@maastrichtuniversity.nl

providing details and we will investigate your claim.
}

Copyright and moral rights for the publications made accessible in the public portal are retained by the authors and/or other copyright owners and it is a condition of accessing publications that users recognise and abide by the legal requirements associated with these

- Users may download and print one copy of any publication from the public portal for the purpose of private study or research.

- You may not further distribute the material or use it for any profit-making activity or commercial gain

If the publication is distributed under the terms of Article 25fa of the Dutch Copyright Act, indicated by the "Taverne" license above,

Download date: 26 Apr. 2023 


\title{
Etomoxir-induced partial carnitine palmitoyltransferase-I (CPT-I) inhibition in vivo does not alter cardiac long-chain fatty acid uptake and oxidation rates
}

\author{
Joost J. F. P. LUIKEN¹, Hanneke E. C. NIESSEN*, Susan L. M. COORT*, Nicole HOEBERS*, Will A. COUMANS*, \\ Robert W. SCHWENK*, Arend BONEN $\dagger$ and Jan F. C. GLATZ* \\ ${ }^{*}$ Department of Molecular Genetics, Cardiovascular Research Institute Maastricht (CARIM), Maastricht University, Universiteitssingel 50, 6200 MD Maastricht, The Netherlands, and \\ $\dagger$ Department of Human Health and Nutritional Sciences, University of Guelph, 50 Stone Road East, Guelph, Ontario, Canada N1G 2W1
}

\begin{abstract}
Although CPT-I (carnitine palmitoyltransferase-I) is generally regarded to present a major rate-controlling site in mitochondrial $\beta$-oxidation, it is incompletely understood whether CPT-I is ratelimiting in the overall LCFA (long-chain fatty acid) flux in the heart. Another important site of regulation of the LCFA flux in the heart is trans-sarcolemmal LCFA transport facilitated by CD36 and FABPpm (plasma membrane fatty acid-binding protein). Therefore, we explored to what extent a chronic pharmacological blockade of the LCFA flux at the level of mitochondrial entry of LCFA-CoA would affect sarcolemmal LCFA uptake. Rats were injected daily with saline or etomoxir, a specific CPT-I inhibitor, for 8 days at $20 \mathrm{mg} / \mathrm{kg}$ of body mass. Etomoxir-treated rats displayed a $44 \%$ reduced cardiac CPT-I activity. Sarcolemmal contents of CD36 and FABPpm, as well as the LCFA transport capacity, were not altered in the hearts of etomoxir-treated versus
\end{abstract}

control rats. Furthermore, rates of LCFA uptake and oxidation, and glucose uptake by cardiac myocytes from etomoxir-treated rats were not different from control rats, neither under basal nor under acutely induced maximal metabolic demands. Finally, hearts from etomoxir-treated rats did not display triacylglycerol accumulation. Therefore CPT-I appears not to present a major rate-controlling site in total cardiac LCFA flux. It is likely that sarcolemmal LCFA entry rather than mitochondrial LCFA-CoA entry is a promising target for normalizing LCFA flux in cardiac metabolic diseases.

Key words: CD36, carnitine palmitoyltransferase-I, long-chain fatty acid uptake, long-chain fatty acid oxidation, mitochondria, sarcolemmal transport.

\section{INTRODUCTION}

LCFAs (long-chain fatty acids) are the major energy source for the heart to sustain contractile activity. Since the heart can store or synthesize LCFAs only in limited amounts, it strongly relies on a continuous LCFA supply from the circulation [1]. LCFAs are taken up mainly via a protein-mediated mechanism, involving two sarcolemmal LCFA-binding proteins, FABPpm [plasma membrane FABP (fatty acid-binding protein)] and CD36 [2]. Kinetic evidence suggests that FABPpm and CD36 operate in concert with each other, so as to make up two components of one functional LCFA transport system. Accordingly, both proteins were found to physically interact, based on co-immunoprecipitation experiments using cardiac sarcolemmal preparations [3]. Moreover, these proteins not only facilitate LCFA uptake, but they also regulate this process via their translocation from intracellular stores to the sarcolemma. Notably, an increase in contractile activity, which increases the metabolic demands of the heart, also causes the translocation of both FABPpm and CD36 to the cell surface to increase LCFA uptake [4].

Immediately after their trans-sarcolemmal transport, LCFAs bind to FABPc (cytoplasmic FABP), which channels them to the mitochondria, where LCFAs are activated by FACS (fatty acylCoA synthetase), located at the cytoplasmic side of the outer mitochondrial membrane $[1,5]$. In the contracting heart, the bulk of LCFA-CoA esters is taken up into the mitochondria via CPT-I (carnitine palmitoyltransferase-I), and subsequently degraded in the $\beta$-oxidation pathway [1]. The portion of the LCFA-CoA esters that is not used for mitochondrial $\beta$-oxidation is mainly esterified into triacylglycerols for storage.

CPT-I is located within the mitochondrial outer membrane, and converts LCFA-CoA into LCFA-carnitine. CPT-I exists in two isoforms, a $\mathrm{L}$ (liver) variant and a $\mathrm{M}$ (muscle) variant [6]. Both isoforms are expressed in cardiac myocytes, but M-CPT-I is the predominant isoform, and contributes $98 \%$ of total cardiac CPTI activity [7]. CPT-I provides a major site of acute regulation of $\beta$-oxidation via its physiological inhibitor malonyl-CoA, and its enzymatic activity towards LCFA-CoA is generally proposed to be the overall rate-limiting step in long-term cellular LCFA utilization [6].

However, indirect observations based on measurements of intracellular malonyl-CoA levels have questioned the role of CPT-I in the regulation of mitochondrial $\beta$-oxidation [5]. Notably, the concentration of malonyl-CoA in the heart was estimated to be $1-10 \mu \mathrm{M}[8,9]$, which greatly exceeds the $\mathrm{IC}_{50}$ of M-CPT-I for malonyl-CoA $(0.02 \mu \mathrm{M}$; [5]). Hence, $\beta$-oxidation would be theoretically permanently blocked if CPT-I was rate-limiting for $\beta$-oxidation. More recently, it was observed in perfused hearts from $d b / d b$ mice that LCFA oxidation was 4-fold increased, independent of changes in CPT-I activity [10]. These observations suggest that CPT-I activity may not be rate-limiting for cardiac $\beta$-oxidation.

Abbreviations used: ACC, acetyl-CoA carboxylase; AMPK, AMP-activated protein kinase; CPT-I, carnitine palmitoyltransferase-I; ECL, enhanced chemiluminescence; FABPc, cytoplasmic fatty acid-binding protein; FABPpm, plasma membrane fatty acid-binding protein; FATP, fatty-acid transport protein; LCFA, Iong-chain fatty acid; L-CPT-I, liver CPT-I; M-CPT-I, muscle CPT-I; OXPHOS, oxidative phosphorylation; PPAR $\alpha$, peroxisome-proliferatoractivated receptor $\alpha$.

1 To whom correspondence should be addressed (email j.luiken@gen.unimaas.nl). 
Another site regulating LCFA oxidation appears to be at the level of the sarcolemma, where LCFA uptake into cardiac myocytes is mediated by the FABPpm/CD36 transport system $[2,4]$. Namely, CD36-mediated LCFA uptake is closely coordinated with subsequent metabolism. This is illustrated by the observation that during the initial LCFA uptake phase, which is considered to be independent of metabolism, the bulk of LCFA is rapidly metabolized [11]. Furthermore, in CD36-null mice, in which CPT-I protein expression is not altered, LCFA oxidation is impaired, particularly during a metabolic challenge [12]. Finally, in $d b / d b$ mice, markedly increased rates of cardiac LCFA oxidation were solely attributable to an elevated content of sarcolemmal CD36, whereas CPT-I activity was unaltered [10].

Taken together, a number of observations in recent years have raised the question whether cardiac LCFA fluxes are only regulated by CPT-I or predominantly by CPT-I in combination with other regulatory mechanisms. Therefore, we sought to partially block CPT-I in the heart by the chronic administration of etomoxir to rats, as has been done previously [13-16]. Thereafter, we measured cardiac triacylglycerol content, LCFA transport and transporters in giant sarcolemmal vesicles and, finally, LCFA uptake and oxidation by cardiac myocytes. We find that in etomoxir-treated rats, despite a marked reduction $(\sim 50 \%)$ in CPT-I activity, the FABPpm-CD36-mediated LCFA uptake is not altered, and LCFA oxidation rates are maintained during both basal and maximal metabolic demands. Therefore, we conclude that under these circumstances CPT-I does not appear to be ratelimiting in regulating cardiac LCFA fluxes.

\section{EXPERIMENTAL}

\section{Materials}

$\left[1-{ }^{14} \mathrm{C}\right]$ Palmitic acid and $\left[{ }^{3} \mathrm{H}\right]$ glucose were obtained from Amersham Life Science (Little Chalfont, U.K.). BSA (fraction V), collagenase type VII and oligomycin were purchased from Sigma (Saint Louis, MO, U.S.A.). Collagenase type II was from Worthington (Freehold, NJ, U.S.A.). Non-fat dried skimmed milk powder (Marvel) was obtained from Premier Brands (Moreton, U.K.). Western blot reagents were from Bio-Rad Laboratories (Hercules, CA, U.S.A.) and the $\mathrm{ECL}^{\circledR}$ (enhanced chemiluminescence) kit was from Amersham Pharmacia Biotech (Buckingham, U.K.). CD36 was detected with a monoclonal antibody (MO25) directed against human CD36, provided by Dr N. Tandon (Otsuka Pharmaceuticals, Bethesda, MD, U.S.A.). A rabbit polyclonal antibody against rat hepatic membrane fatty acid binding protein was used to detect FABPpm (gift from Dr D. Sorrentino, Mount Sinai Medical Center, New York City, NY, U.S.A.). M-CPT1 antibodies were a gift from Dr G. Woldegiorgis (Oregon Graduate Institute of Science and Technology, Beaverton, OR, U.S.A.). An antibody directed against $\mathrm{Ser}^{79}$-phosphorylated ACC (acetyl-CoA carboxylase) was from Upstate (Dundee, U.K.). Mitochondrial OXPHOS (oxidative phosphorylation) complexes were detected using a monoclonal antibody kit from MitoSciences (Eugene, OR, U.S.A.). Rabbit anti-mouse immunoglobulin horseradish peroxidase and pig anti-rabbit immunoglobulin horseradish peroxidase were obtained from DAKO (Glostrup, Denmark). Etomoxir was purchased from Dr H.P.O. Wolf (Projekt Entwicklung GmbH, Allensbach, Germany).

\section{Animals}

Male Lewis rats, weighing 150-200 g, were used in the present study. Animals were kept on a 12 h:12 h light/dark cycle and fed a Purina Chow diet and water ad libitum. The rats were divided into two groups: (1) control and (2) etomoxir. Etomoxir $(20 \mathrm{mg} / \mathrm{kg}$ of body weight) was dissolved in $0.9 \%(\mathrm{w} / \mathrm{v}) \mathrm{NaCl}$ and administered intraperitoneally for 8 days. Control rats received saline. The last injection was given $24 \mathrm{~h}$ before the experiment. Ethical approval for all experimental procedures was obtained from the Experimental Animal Committee of the Maastricht University, and the study conforms to the Guide for the Care and Use of Laboratory Animals published by the US National Institutes of Health (NIH Publication No. 85-23, revised 1996). Animals were anaesthetized with an intraperitoneal injection of a nembutal and heparin (3:1) mixture. Subsequently, the heart was removed for LCFA uptake studies and for analyses of transporter protein contents.

\section{Isolation of giant sarcolemmal vesicles for determination of palmitate transport and transporters}

Giant vesicles were prepared from heart muscle, as previously described [2]. These vesicles are solely derived from plasma membrane, and are virtually uncontaminated with intracellular membranes. LCFAs do not merely loosely associate with giant vesicles, but are taken up across the vesicle membrane. Within the lumen of the vesicles, FABPc is abundantly present to act as an LCFA sink [2]. These giant vesicles were used for the assessment of the sarcolemmal content of LCFA transporters (see below). These vesicles were also used for the measurement of the cardiac LCFA uptake capacity, as previously described in [2].

\section{Isolation of cardiac myocytes}

Cardiac myocytes were isolated from control or etomoxir-treated rats using a Langendorff perfusion system and a Krebs-Henseleit bicarbonate buffer equilibrated with $95 \%(\mathrm{v} / \mathrm{v}) \mathrm{O}_{2}$ and $5 \%(\mathrm{v} / \mathrm{v})$ $\mathrm{CO}_{2}$ (medium A) at $37^{\circ} \mathrm{C}$ as previously described [11]. Cells were only used for subsequent tracer uptake studies when $>80 \%$ of the cells had a rod-shaped appearance.

\section{Palmitate utilization by cardiac myocytes}

Cells $(2.0 \mathrm{ml} ; 8-12 \mathrm{mg}$ of wet mass $/ \mathrm{ml})$ were preincubated in $20 \mathrm{ml}$ vials in the absence or presence of $30 \mu \mathrm{M}$ oligomycin for $15 \mathrm{~min}$ at $37^{\circ} \mathrm{C}$ under continuous shaking. At the start of the incubations, a mixture of $\left[1-{ }^{14} \mathrm{C}\right]$ palmitate/BSA complex and $\left[1-{ }^{3} \mathrm{H}\right]$ deoxyglucose was added to cell suspensions (final concentrations: $100 \mu \mathrm{M}$ or $600 \mu \mathrm{M}$ palmitate with corresponding palmitate/BSA ratios of 0.33 or 2.0 respectively; and $100 \mu \mathrm{mol} / \mathrm{l}$ deoxyglucose) as previously described. Uptake of $\left[{ }^{14} \mathrm{C}\right]$ palmitate and $\left[{ }^{3} \mathrm{H}\right]$ deoxyglucose (over $3 \mathrm{~min}$ ) was determined by scintillation counting. Oxidation of $\left[{ }^{14} \mathrm{C}\right]$ palmitate (20 min incubation) into $\mathrm{CO}_{2}$ via base trapping was determined after addition of perchloric acid $(0.5 \mathrm{M})$ to cell suspensions [11].

\section{Oxygen consumption by cardiac myocytes}

Incubations for measurement of oxygen consumption were performed in a specially designed vial with a total volume of $7 \mathrm{ml}$. Because a gas phase disturbs oxygen consumption measurements, the incubation vial was completely filled with a cell suspension (5-8 mg of wet mass $/ \mathrm{ml}$ ) that was saturated with $95 \%$ (v/v) $\mathrm{O}_{2}$ and $5 \%(\mathrm{v} / \mathrm{v}) \mathrm{CO}_{2}$ immediately before capping the vial. Under continuous shaking at $37^{\circ} \mathrm{C}$, oxygen consumption was measured with a Clark-type electrode. Hence, measurements started with a $\mathrm{pO}_{2}$ between 500 and $600 \mathrm{mmHg}$. Furthermore, measurements were corrected for loss of oxygen due to consumption by the Clarke electrode and to diffusion. 


\section{Sample preparation for Western blotting and CPT-I activity measurement}

Total tissue homogenates to be used for Western blotting and for CPT-I activity measurement were prepared from heart and, for reference, from liver. Briefly, tissues (approx. $50 \mathrm{mg}$ ) were homogenized in $1 \mathrm{ml}$ of Tes buffer $(10 \mathrm{mM}$ Tris/ $\mathrm{HCl}, 2 \mathrm{mM}$ di-Na-EDTA and $250 \mathrm{mM}$ sucrose, $\mathrm{pH}$ 7.4) supplemented with PMSF and DMSO for 5 interrupted $5 \mathrm{~s}$ bursts with an Ultra Turrax homogenizer (IKA, Staufen, Germany) set at 24000 rev./min. Thereafter, cells were disintegrated in 4 cycles ( $5 \mathrm{~s}$ on, $15 \mathrm{~s}$ off) with an amplitude of 10-12 using an Ultrasonic Disintegrator (Soniprep 150, Sanyo Gallenkamp Plc.). Protein concentration was determined and samples were stored at $-80^{\circ} \mathrm{C}$.

\section{SDS/PAGE and Western blotting}

Total tissue homogenates $(20 \mu \mathrm{g})$ and giant vesicle preparations (3 $\mu \mathrm{g})$ respectively, were separated by SDS/PAGE on $12.5 \%$ $(\mathrm{w} / \mathrm{v})$ acrylamide gels at $150 \mathrm{~V}$ and room temperature $\left(21^{\circ} \mathrm{C}\right)$. Subsequently, proteins were transferred on to nitrocellulose membranes by Western blotting and detected for CD36, FABPpm, ACC, CPT-I and OXPHOS complexes. Western blotting for the detection of CD36, FABPpm [2] and CPT-I [17] was performed as described previously, and for the detection of OXPHOS complexes according to the manufacturer's instruction. The protein bands were visualized using ECL, and immunoblot intensities were analysed by using densitometry using Quantity One software (Bio-Rad Laboratories, Hercules, CA, U.S.A.).

\section{Assay of CPT-1 activity}

CPT-I activity was assayed in total tissue homogenates by the CPT-forward measurement. In this assay, palmitoylcarnitine formation from palmitoyl-CoA and an ATP-regenerating system was determined as previously described in [18].

\section{Assay of intracellular triacylglycerol content}

Upon thawing, pieces of heart and liver tissue $(20 \mathrm{mg}$ wet mass) from control and etomoxir-treated rats were subjected to lipid extraction and TLC, after which TLC plates were sprayed with a mixture of rhodamine B-6G and fluorescein in methanol for UV detection using a Fluor-S-MultiImager (Bio-Rad Laboratories, Hercules, CA, U.S.A.). These methods are detailed by Hasselbaink et al. [19]. Spots were quantified using QuantityOne software (Bio-Rad Laboratories).

\section{Other procedures}

Blood glucose was determined by use of a Euroflash ${ }^{\circledR}$ pocketscan blood glucose meter (Lifescan, Milpitas, CA, U.S.A.). Cellular wet mass was obtained from cell samples taken during the incubation period and determined after centrifugation for 2$3 \mathrm{~s}$ at maximal speed in a microcentrifuge and subsequent removal of the supernatant. Protein was quantified with the bicinchoninic acid protein assay (Pierce, Rockford, IL, U.S.A.) according to the manufacturer's instructions.

\section{Statistics}

All results are reported as means \pm S.E.M. Statistical difference between groups was tested with a Student's $t$ test, or the MannWhitney $U$ test for not normally distributed data. $P$ values equal to or less than 0.05 were considered significant.
Table 1 Characteristics of rats treated for 8 days with $20 \mathrm{mg} / \mathrm{kg}$ etomoxir Results are means \pm S.E.M., ${ }^{*} P<0.05$, etomoxir-treated rats $(n=6)$ versus control rats $(n=6)$.

\begin{tabular}{lcc}
\hline Parameter & Control & Etomoxir \\
\hline Body mass $_{\text {begin }}(\mathrm{g})$ & $227 \pm 9$ & $228 \pm 10$ \\
Body mass $_{\text {end }}(\mathrm{g})$ & $256 \pm 9$ & $253 \pm 9$ \\
$\Delta$ Body mass $(\mathrm{g})$ & $29 \pm 3$ & $25 \pm 4$ \\
Heart mass $(\mathrm{g})$ & $0.79 \pm 0.02$ & $0.88 \pm 0.03^{*}$ \\
Heart mass/body mass $\left(\times 10^{3}\right)$ & $3.70 \pm 0.20$ & $4.10 \pm 0.20$ \\
Liver mass $(\mathrm{g})$ & $10.6 \pm 0.3$ & $11.9 \pm 0.4^{*}$ \\
Liver mass/body mass $\left(\times 10^{3}\right)$ & $41.3 \pm 1.1$ & $46.9 \pm 1.5^{*}$ \\
Hindlimb mass $(\mathrm{g})$ & $1.50 \pm 0.05$ & $1.50 \pm 0.03$ \\
Hindlimb mass/body mass $\left(\times 10^{3}\right)$ & $5.87 \pm 0.02$ & $5.94 \pm 0.11$ \\
Plasma glucose $(\operatorname{mmol} / \mathrm{l})$ & $7.50 \pm 0.23$ & $7.76 \pm 0.37$ \\
& & \\
\hline
\end{tabular}

\section{RESULTS}

\section{Characteristics of etomoxir-treated rats}

The treatment of Lewis rats for 8 days with $20 \mathrm{mg} / \mathrm{kg}$ etomoxir did not alter blood glucose, which is in line with comparable etomoxirfeeding studies $[13,15,16]$. Similarly, etomoxir feeding did not affect general growth characteristics such as gain in body mass, nor did it affect hindlimb muscle mass (Table 1). However, heart mass and liver mass were both significantly increased by $11 \%$ in etomoxir-treated rats. Such cardiac and hepatic hypertrophy has previously been described in other etomoxir-feeding studies (e.g. see $[13,14,20]$ ), and provides confirmation that the present etomoxir treatment was effective.

\section{Effects of etomoxir on cardiac and hepatic CPT-I activity/expression and triacylglycerol contents}

As expected, chronic administration of etomoxir induced decreases in CPT-1 activity in heart $(-44 \%)$ and liver $(-56 \%$; Figure 1A). Remarkably, the expression of the M-CPT-I protein in the heart was increased by 1.7 -fold (Figure 2A), which could possibly reflect a compensatory mechanism. In contrast, expression levels of the OXPHOS complexes I, II and V were unchanged between hearts of control and etomoxir-treated rats, indicating that the etomoxir-induced up-regulation of CPT-I expression was not accompanied by an overall increase in mitochondrial protein content (Figure 2B).

Administration of etomoxir to rodents is known to have marked effects on body lipid stores (e.g. see [14,20]). With respect to cardiac lipid pools, we examined only the intramyocellular triacylglycerol content, because this is the major intracellular depot of LCFA [11]. The intramyocellular triacylglycerol content was not altered in etomoxir-treated rats (Figure 1B). In contrast, in liver there was a 2.1-fold increase in triacylglycerol content (Figure 1B).

\section{Effects of etomoxir on cardiac LCFA transport and transporters}

The protein expressions of both FABPpm and CD36 were not altered by etomoxir-treatment (Figure 3B). Since it is not the total tissue expression of these transporters that determines the rate of LCFA uptake but rather their localization at the cell surface, giant sarcolemmal vesicles were prepared from cardiac tissue to study the presence of these transporters at the sarcolemma. In previous studies we have shown that these giant vesicles are purely derived from myocytic sarcolemma [2]. In agreement, the muscle-specific caveolin isoform, caveolin-3, was found to be enriched in giant vesicles compared with total tissue homogenates, whereas CPT-I was not detectable, indicating that there is no 
A

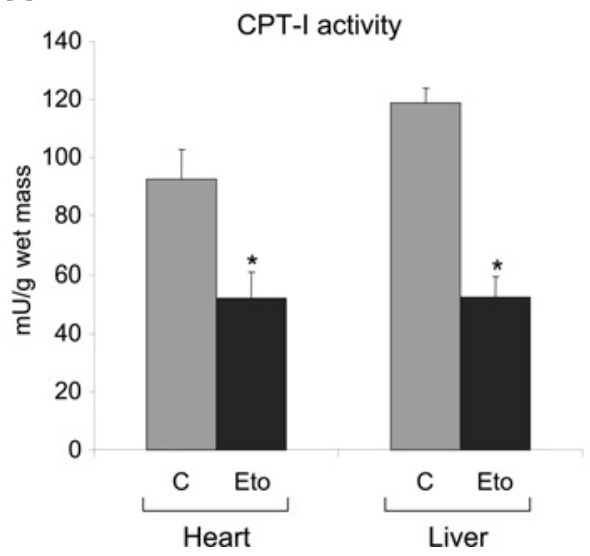

B

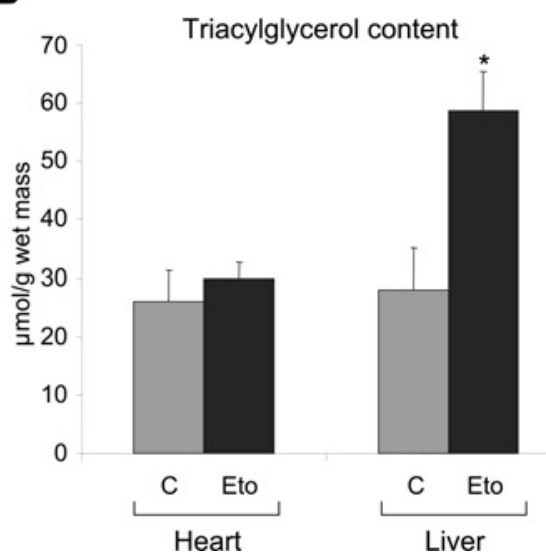

Figure 1 Effects of in vivo etomoxir treatement on CPT-I activity and triacylglycerol content in heart and liver

(A) CPT-I activity was measured in tissue homogenates, and (B) triacylglycerol content was measured in pieces of tissue as described in the Experimental section. Results are means \pm S.E.M. for experiments carried out with tissue preparations from four control rats $(C)$ and four etomoxir-treated rats (Eto). ${ }^{*}$ Significantly different from control $(P<0.05)$.

A

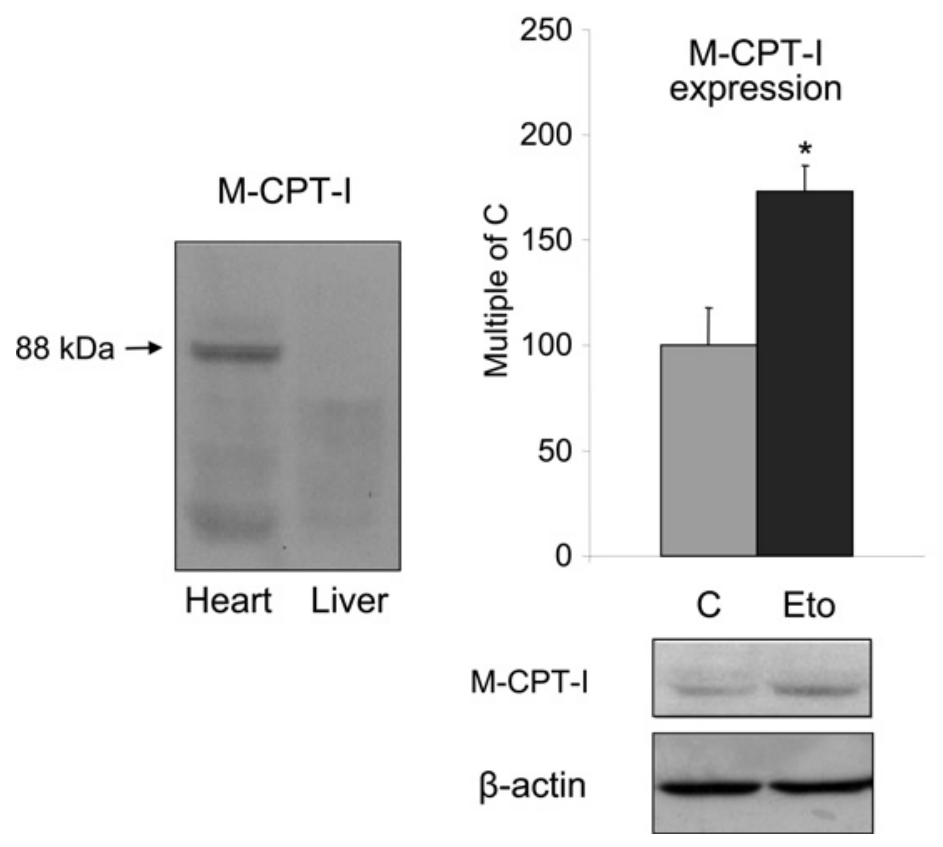

B

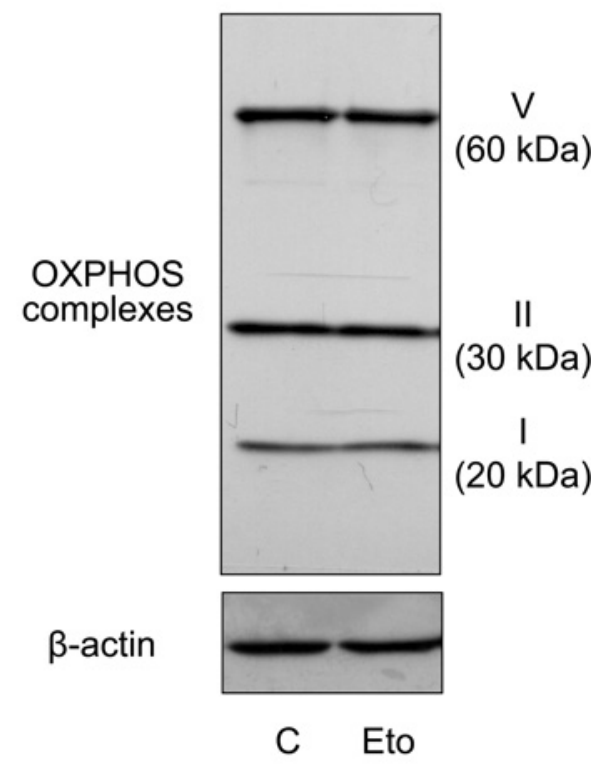

Figure 2 Effect of in vivo etomoxir treatment on expression of M-CPT-I and OXPHOS complexes in the heart

Contents of (A) M-CPT-I and (B) OXPHOS complexes were measured in heart homogenates using Western blotting. (A) The Western blot left of the graph demonstrates that the used antibody (a gift from Professor V. Zammit, Hannah Research Institute, Scotland, U.K.) is specific against M-CPT-I. Namely, an $88 \mathrm{kDa}$ signal was detected in the heart, corresponding to the reported molecular mass of M-CPT-I [6], whereas such a signal was undetectable in liver, which expresses only L-CPT-I. Gels were loaded with equal quantities of protein for each cell lysate (50 $\mu \mathrm{g}$ per lane). Representative blots are shown comparing cardiac expression levels of (A) M-CPT-I, (B) OXPHOS complexes, and $\beta$-actin (loading control, detected at $45 \mathrm{kDa}$ ) between control and etomoxir-treated rats. Complex I was detected at $20 \mathrm{kDa}$, complex II at $30 \mathrm{kDa}$ and complex $\mathrm{V}$ at $60 \mathrm{kDa}$. Results are means \pm S.E.M. for experiments carried out with heart homogenates from six rats in each group. C, control rats; Eto, etomoxir-treated rats. *Significantly different from control $(P<0.05)$.

contamination of mitochondria (Figure 3A), and also not of other subcellular organelles [21]. In line with their total tissue expression, sarcolemmal localizations of both FABPpm and CD36 were not altered (Figure 3C).

The giant vesicles also are suitable for determining the uptake capacity of LCFA across the sarcolemma into the heart, because: (i) in these vesicles all transporters are fixed at the vesicle surface (due to absence of transporter recycling processes between vesicle lumen compartments and the surface); and (ii) LCFA transport rates are measured independently from their metabolism [2]. The LCFA uptake capacity into cardiac-derived giant sarcolemmal vesicles was not altered by the etomoxir treatment (Figure 3D). Thus, despite the chronic inhibition of CPT-I in etomoxir-treated hearts, there were no concurrent changes in sarcolemmal LCFA transport capacity, nor in the expression and the subcellular localization of LCFA transporters. 
A

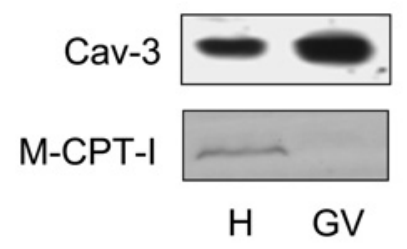

B
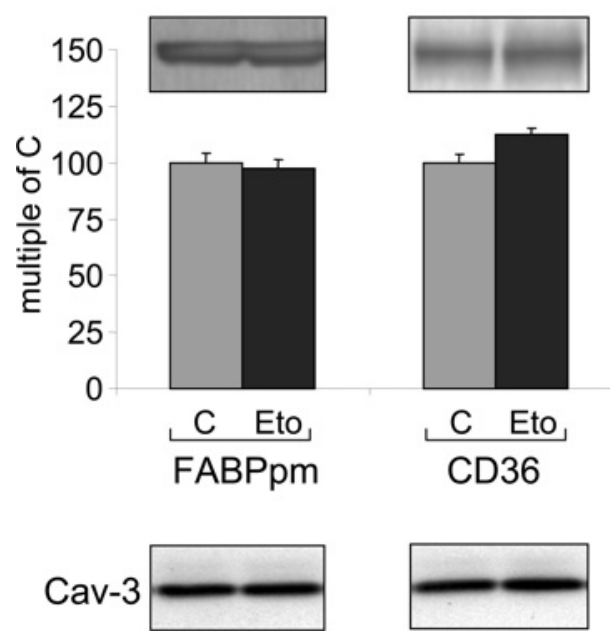

C Sarcolemmal protein

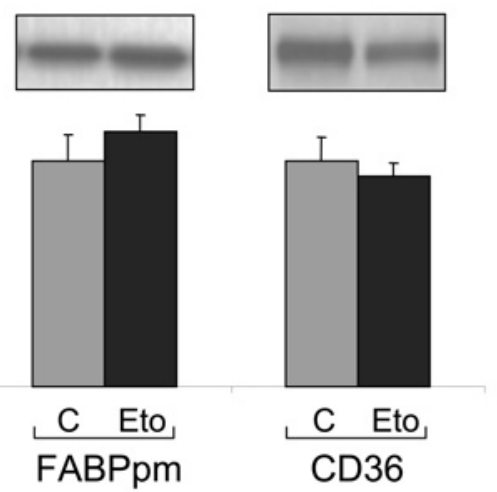

\section{Palmitate uptake}

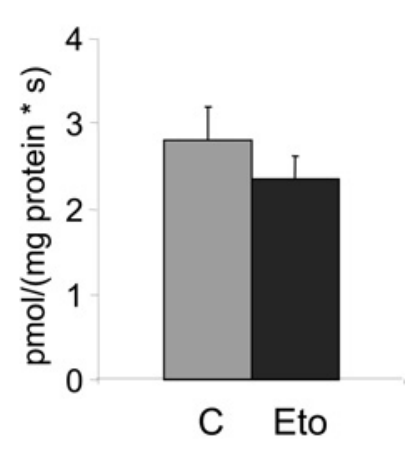

Figure 3 Effect of in vivo etomoxir treatment on expression and sarcolemmal localization of FABPpm and CD36 in the heart and on cardiac LCFA transport capacity

(A) Characterization of giant vesicles as sarcolemmal preparation. Heart homogenates (H) and heart giant vesicles (GV) were prepared as described in the Experimental section, and used for measurement of contents of caveolin-3 and CPT-I. (B) Heart homogenates were used for measurement of total tissue expression of FABPpm and CD36 (total protein), and giant vesicles were used to (C) detect both transporters at the sarcolemma (sarcolemmal protein), and to (D) measure palmitate uptake. Representative Western blots are shown. Caveolin-3 was detected at $18 \mathrm{kDa}$, CPT-I at $88 \mathrm{kDa}$, FABPpm at $43 \mathrm{kDa}$, and CD36 at $88 \mathrm{kDa}$. Results are means \pm S.E.M. for experiments carried out with heart homogenates or vesicle preparations from 6 rats in each group. C, control rats; Eto, etomoxir-treated rats.

\section{Effects of etomoxir on the dynamics of LCFA uptake and oxidation by cardiac myocytes}

Cardiac myocytes were chosen as the preferential model to measure cardiac LCFA fluxes because the extracellular environment can be fully controlled while both vascular factors and the endothelial barrier are eliminated. Furthermore, the large extracellular space in incubations of cardiac myocytes allows the exogenous LCFA concentration to remain constant during the initial uptake period, which avoids complicated calculations and assumptions in the case of the limited vascular space in the perfused working heart, where the substrate becomes rapidly depleted. However, compared to working hearts, metabolic rates of non-contracting myocytes are lower. Thus basal oxygen consumption amounted to $20.5 \pm 2.2 \mu \mathrm{l}$ of $\mathrm{O}_{2} / \mathrm{g}$ of wet mass per min $(n=3)$, in agreement with measurements of others [22]. This is $10-15 \%$ of the oxygen consumption by the working rat heart (e.g. see [23]). For stimulation of metabolic rates of cardiac myocytes, we applied the mitochondrial inhibitor oligomycin. Oligomycin, at an optimal concentration of $30 \mu \mathrm{M}$, effectively blocks the $\mathrm{F}_{1} \mathrm{~F}_{0}$-type proton pump while not affecting the electron transfer chain $[4,24]$. Oxygen consumption by oligomycin-treated cardiac myocytes amounted to $146.6 \pm 10.6 \mu \mathrm{l}$ of $\mathrm{O}_{2} / \mathrm{g}$ of wet mass per $\min (n=3)$, which is 7.2 -fold higher than by their non-stimulated counterparts, and closely resembles the oxygen consumption of the working heart of approx. $180 \pm 50 \mu \mathrm{l}$ of $\mathrm{O}_{2} / \mathrm{g}$ of wet mass per min. Oligomycin treatment also results in increased intracellular AMP/ATP levels, and consequently, activation of AMPK (AMP-activated protein kinase). In its turn, AMPK phosphorylates ACC at $\mathrm{Ser}^{79}$, resulting in an inhibition of its enzymatic activity and a subsequent reduction in intracellular malonyl-CoA levels. In cardiac myocytes from both control and etomoxir-treated rats, oligomycin treatment resulted in a similar ( $>5$-fold in both cases) increase in ACC-Ser ${ }^{79}$ phosphorylation (Figure 4), indicating that chronic exposure of rats to etomoxir did not affect upstream events regulating CPT-I activity, most notably acute modulation of malonyl-CoA levels by ACC.

We have studied the effects of oligomycin on LCFA uptake at externally added palmitate concentrations of 100 and $600 \mu \mathrm{M}$, reflecting low and high physiological concentrations of this substrate as occurring in the cardiac interstitial space [2]. Similarly to our observations in giant vesicles, basal LCFA uptake was not significantly altered in cardiac myocytes from etomoxir-treated rats, either at 100 or $600 \mu \mathrm{M}$ palmitate (Figures 5A and 5B). At both palmitate concentrations, addition of $30 \mu \mathrm{M}$ oligomycin increased LCFA uptake into cardiac myocytes from control- and etomoxir-treated rats by $\sim 1$.4-fold (Figures $5 \mathrm{~A}$ and $5 \mathrm{~B}$ ). 


\section{Phosphorylation of ACC at Ser79}

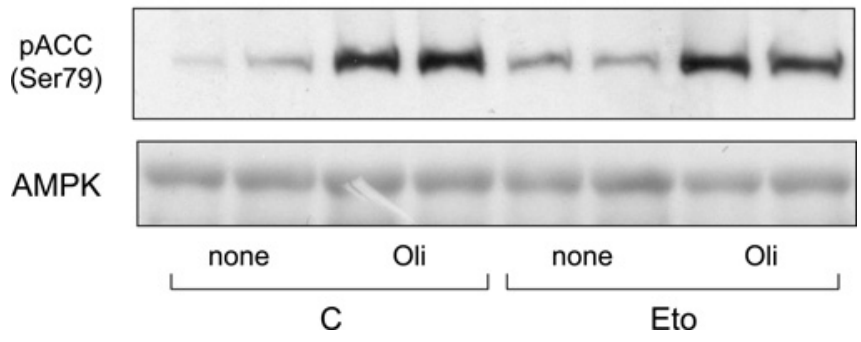

Figure 4 Effect of in vivo etomoxir treatment on phosphorylation of ACC in oligomycin-stimulated cardiac myocytes

Cardiac myocytes were isolated from contol rats $(\mathrm{C}$ ) and etomoxir-treated rats (Eto). Cardiac myocytes were then incubated for $15 \mathrm{~min}$ in the absence (none) or presence of $30 \mu \mathrm{M}$ oligomycin (Oli). For assessment of cellular content of AMPK $\alpha 2$ (predominant isoform of the catalytic $\alpha$-subunit of AMPK in the heart, detected at $63 \mathrm{kDa}$ and used as loading control) and of phosphorylation of ACC at Ser ${ }^{79}$ [pACC (Ser79)], cardiac myocytes were pelleted, dissolved in sample buffer, after which Western blots were performed with phosphospecific antibodies. Gels were loaded with equal quantities of protein for each cell lysate (50 $\mu \mathrm{g}$ per lane). A representative Western blot is presented out of three experiments.

Likewise, the basal LCFA oxidation rates did not differ between cardiac myocytes from control and etomoxir-treated rats (Figures 5C and 5D). In the presence of oligomycin, palmitate oxidation was similarly stimulated to the same extent $(\sim 6.8$-fold $)$ in cardiac myocytes from control and etomoxir-treated rats (Figures 5C and 5D).

Basal glucose uptake into cardiac myocytes was similar between control and etomoxir-treated rats incubated with $100 \mu \mathrm{M}$ palmitate (Figure 5E). At $600 \mu \mathrm{M}$ palmitate, basal glucose uptake into cardiac myocytes from both rat groups was 5-fold lower (Figure 5F), which is probably due to LCFA-induced inhibition of glucose metabolism according to the principles of the Randle cycle [25]. Oligomycin treatment similarly enhanced glucose uptake by 3.8-fold into cardiac myocytes from control and etomoxir-treated rats incubated with $100 \mu \mathrm{M}$ palmitate (Figure 5E), and by 17 -fold when incubated with $600 \mu \mathrm{M}$ palmitate (Figure 5F).

\section{DISCUSSION}

The primary purpose of this study was to assess the role of CPT-I in the control of cardiac LCFA fluxes. In etomoxir-treated rats, a chronic reduction of cardiac CPT-I activity by $44 \%$ did not adversely alter: (i) cardiac CD36 and FABPpm expression and sarcolemmal localization; (ii) cardiac sarcolemmal LCFA transport capacity; and (iii) cardiac triacylglycerol deposition. The partial CPT-I reduction also did not affect: (iv) LCFA uptake rates; (v) LCFA oxidation rates; and (vi) glucose uptake rates into cardiac myocytes both under basal and under acutely induced maximal metabolic demands in combination with either physiologically low or high LCFA supply. Collectively, these results indicate that reducing CPT-I activity does not impair any aspect of LCFA and glucose metabolism in the heart.

\section{A partial reduction in CPT-I activity is not rate-limiting for cardiac LCFA utilization}

Etomoxir is a commonly used irreversible inhibitor of CPT-I, which results in blocking the entry of long-chain fatty acylmoieties into mitochondria, and a subsequent reduction in the rate of $\beta$-oxidation. Etomoxir is an effective CPT-I inhibitor in the heart, since its addition in micromolar concentrations to cardiac myocytes in vitro inhibited LCFA oxidation by $>95 \%$ [11]. In the present study in vivo, using a daily dose of $20 \mathrm{mg} / \mathrm{kg}$ of body mass, CPT-I activity was partially blocked by $44 \%$. However, expression of M-CPT-I, the major cardiac isoform, was increased by 1.7 -fold. This compensatory upregulation presumably prevented a more dramatic reduction in total CPT-I activity, with more severe consequences for body lipid homoeostasis.

CPT-1 has long been considered the key regulatory enzyme involved in mitochondrial uptake of LCFA $[1,6]$. However, its role in the control of the cardiac LCFA fluxes is incompletely understood [26]. In the theoretical case that CPT-I would be a major control site of cardiac LCFA fluxes, it would probably exert a feedback inhibition on the sarcolemmal LCFA uptake process to prevent an intracellular accumulation of toxic LCFA metabolites. This feedback inhibition of sarcolemmal LCFA uptake might include a possible repression of CD36 and FABPpm and/or an internalization of these LCFA transporters. According to the fluxcontrol theory [5,27], a $\sim 40-50 \%$ inhibition in CPT-I would theoretically result in at least a partial inhibition of cellular LCFA uptake. However, despite marked reductions in CPT-I activity, there were no adverse effects on the expression and subcellular localization of LCFA transporters, nor on the sarcolemmal LCFA transport capacity or cellular LCFA uptake rates under basal and maximal metabolic demands.

Notwithstanding that CPT-I reduction does not have any impact on sarcolemmal LCFA transport and transporters, a more restricted control on mitochondrial $\beta$-oxidation would be expected $[1,6]$. Again, a $~ 50 \%$ reduction of CPT-I activity would be expected to result in a $\sim 50 \%$ reduction of mitochondrial $\beta$-oxidation, according to the flux-control theory of rate-limiting enzymes [27]. However, chronic reduction of CPT-I by $44 \%$ was without any effect on LCFA oxidation, even under maximal substrate supply. Moreover, powerful stimulation of LCFA oxidation by short-term (15 min) oligomycin-induced AMPK activation and subsequent ACC inhibition was not affected by the etomoxir treatment. Hence, the $56 \%$ residual CPT-I levels are sufficient to allow maximal (acute) up-regulation of LCFA oxidation. These findings by themselves do contra-indicate the view that CPT-I is rate-limiting in mitochondrial $\beta$-oxidation. Importantly, this conclusion is in agreement with previous more indirect observations concerning the marked up-regulation of mitochondrial $\beta$-oxidation in hearts from $d b / d b$ mice in the absence of changes in CPT-I expression [10], and provides an explanation for the paradoxical observation that the estimated intramyocellular malonyl-CoA concentration exceeds the $\mathrm{IC}_{50}$ of M-CPT-I for malonyl-CoA by $>50$-fold (see the Introduction section) $[5,8,9]$.

Furthermore, etomoxir treatment had no effect on the intramyocellular triacylglycerol concentration, and therefore the $\sim 50 \%$ CPT-I activity reduction does not result in a compensatory increase in triacylglycerol esterification of LCFA taken up into cardiac myocytes. Finally, etomoxir treatment does not affect glucose uptake, which would have been expected to increase in a secondary response to a hypothetical reduction of $\beta$-oxidation according to the principles of the Randle cycle [25]. Taken together, a $\sim 50 \%$ reduction in CPT-I failed to reduce any aspect of cardiac LCFA utilization, pointing towards a more permissive, rather than a regulatory, role for CPT-I in mediating cardiac LCFA fluxes.

Importantly, this conclusion on the lack of flux control exerted by CPT-I in the heart may be tissue-specific. In other tissues, CPT-I might still be important in the control of mitochondrial $\beta$-oxidation. An example would be the liver, where L-CPT-I is the predominant isoform, which is far less sensitive than 
Incubation with low palmitate $(100 \mu \mathrm{M})$
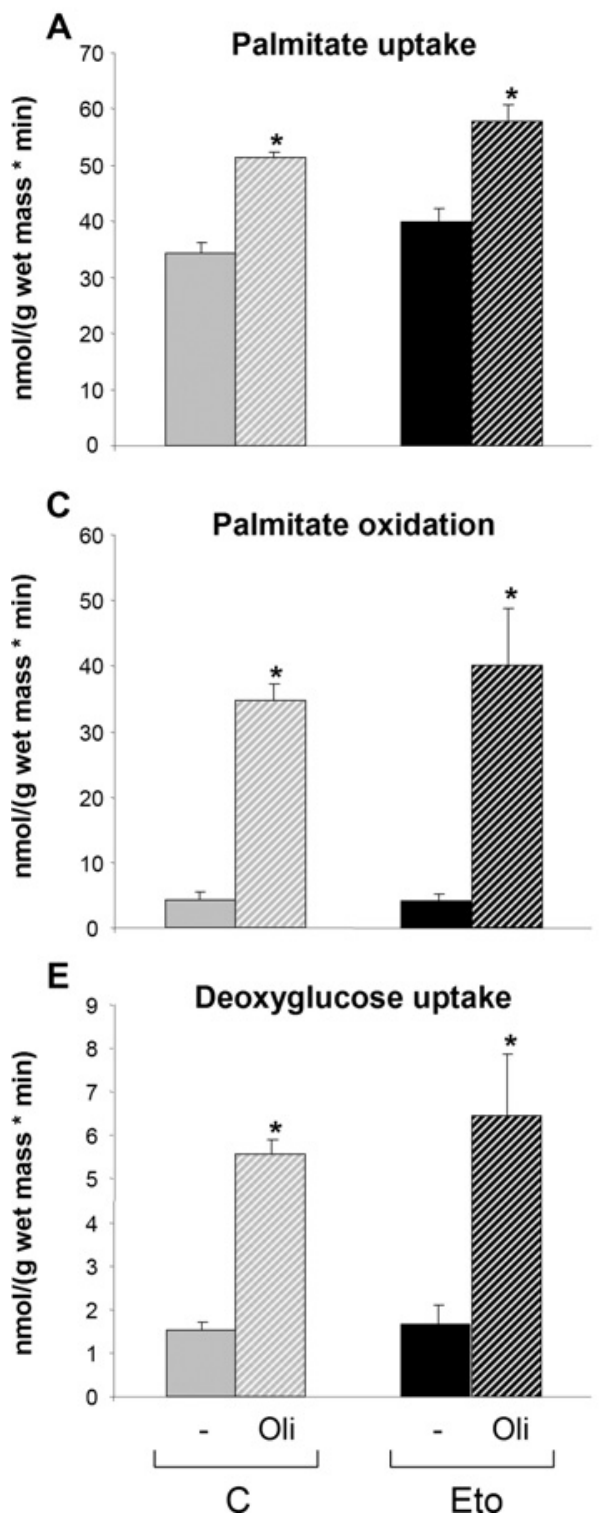

Incubation with high palmitate $(600 \mu \mathrm{M})$

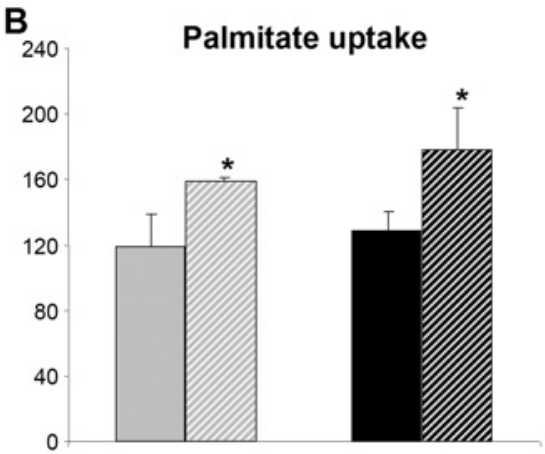

D

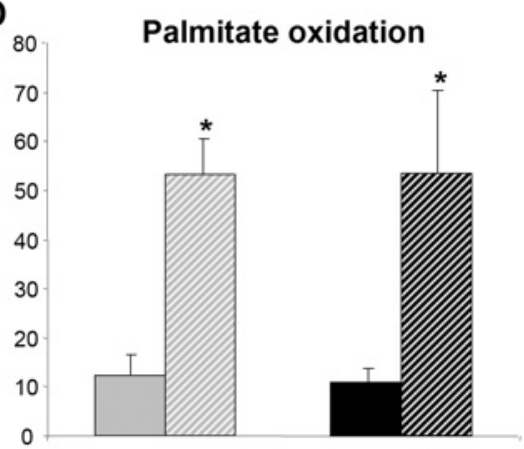

$\mathbf{F}$

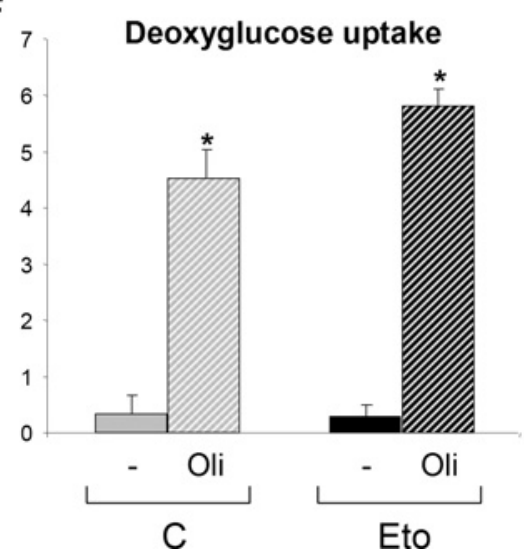

Figure 5 Effect of in vivo etomoxir treatment on substrate utilization into cardiac myocytes

Cardiac myocytes were isolated from contol rats $(\mathrm{C})$ and etomoxir-treated rats (Eto). Cardiac myocytes were then incubated for $15 \mathrm{~min}$ in the absence or presence of $30 \mu \mathrm{M}$ oligomycin (Oli), and subsequently used for measurement of palmitate uptake (A and $\mathbf{B})$, palmitate oxidation $(\mathbf{C}$ and $\mathbf{D})$, and deoxyglucose uptake $(\mathbf{E}$ and $\mathbf{F})$ at $100 \mu \mathrm{M}(\mathbf{A}, \mathbf{C}$ and $\mathbf{E})$ and $600 \mu \mathrm{M}(\mathbf{B}, \mathbf{D}$ and $\mathbf{F})$ externally added palmitate. Light grey bars represent non-stimulated cardiac myocytes from control rats and etomoxir-treated rats. Corresponding dark bars represent oligomycin-treated cardiac myocytes from control rats and etomoxir-treated rats. Results are means \pm S.E.M. for experiments carried out with cardiac myocyte preparations from six rats in each group. *Significantly different from control $(P<0.05)$.

M-CPT-I to inhibition by malonyl-CoA [5]. In the present study, we observed a $56 \%$ reduction in hepatic CPT-I activity with the etomoxir treatment. However, in contrast with the heart, in which triacylglycerols did not accumulate, the liver exhibited a 2.1-fold increase in triacylglycerol content, indicating that modulation of CPT-I activity has an impact on hepatic LCFA metabolism.

\section{Etomoxir-induced cardiac hypertrophy is not caused by changes in cardiac LCFA utilization}

Chronic etomoxir treatment of rats has been frequently used as a rodent model to study the molecular mechanisms underlying the development of cardiac hypertrophy. Indeed, in the present study, etomoxir treatment caused an $11 \%$ increase in heart mass. Etomoxir-induced cardiac hypertrophy was accompanied by an elevated expression of myosin isoform $\mathrm{V}_{1}$, sarcoplasmic reticulum $\mathrm{Ca}^{2+}$-ATPase $[13,28]$ and $\mathrm{Na}^{+}-\mathrm{K}^{+}$-ATPase [29]. The mechanism by which etomoxir induces the expression of myosin isoform $\mathrm{V}_{1}$ and sarcoplasmic reticulum $\mathrm{Ca}^{2+}$-ATPase is incompletely understood, but is probably connected with inhibition of CPT-I and the resulting chronic metabolic shift from LCFA oxidation to glucose utilization [30]. Hence the metabolic switch induced by CPT-I blockade is considered a key signal for this type for cardiac remodelling. Therefore transcription factors sensitive 
to changes in LCFA or LCFA metabolites are considered as likely candidates in the switch in genetic programming [31]. However, the present study, in which etomoxir-induced CPT-I inhibition did not alter cardiac LCFA utilization, suggests that the switch in gene expression might not be due to LCFA- (or LCFA metabolite-) induced transcription factors. Indeed, PPAR $\alpha$ (peroxisome-proliferator-activated receptor $\alpha$ ) expression and $\operatorname{PPAR} \alpha$ target genes were not increased in chronic etomoxir treatment of mice [16]. Interestingly, it has been reported that etomoxir (or its metabolite etomoxiryl-CoA) activates other transcription factors via LCFA-independent mechanisms. In this respect, etomoxir-induced down-regulation of peroxisomal acylCoA oxidase appeared to cause oxidative stress and, hence, NF$\kappa \mathrm{B}$ (nuclear factor $\kappa \mathrm{B}$ ) activation [16].

\section{Implications for treatment of cardiac metabolic diseases}

There is emerging evidence that cardiac diseases are, at least partially, caused by alterations in cardiac energy substrate metabolism. For instance, the insulin resistant/Type 2 diabetic heart shows increased LCFA uptake and oxidation, which is accompanied by diastolic malfunctioning [32-34]. Therefore, therapeutic manipulations to reduce the cardiac LCFA flux should be beneficial for the diseased heart and restore cardiac function $[3,35,36]$. Moreover, because heart failure decreases the energy reserve of the heart and LCFA oxidation is less efficient in terms of oxygen consumption than glucose oxidation $[35,36]$, this would provide another reason why reduction of LCFA fluxes might improve cardiac contractile parameters. The most efficient target for such therapy is the rate-limiting step in cardiac LCFA utilization. On the basis of the present results, it appears that CPT-I does not represent the predominant control site. Instead, there is growing evidence that cardiac LCFA fluxes are regulated at the level of the LCFA transport system consisting of FABPpm and $\mathrm{CD} 36$, i.e. via altered distribution of these transporters between intracellular membrane compartments (endosomes) and the sarcolemma [3]. Also, other LCFA transporters have been proposed to function in mammalian tissues, such as members of the FATP (fatty-acid transport protein) family, caveolin-1 and a putative adipocyte membrane protein pump [37], but the expression of the first two proteins is restricted to adipocytes $[21,37]$, and FATPs have been shown not to play a major role in bulk LCFA uptake into the heart $[2,38]$. In this light, agents reducing the flux through FABPpm and CD36, rather than CPT-I inhibitors, would seem to be the preferable therapeutic agents for the treatment of cardiac disease.

\section{ACKNOWLEDGEMENTS}

We thank Mr J. Willems for excellent technical assistance. Furthermore, we thank Dr Tandon for providing the antibodies against FAT/CD36, Dr Sorrentino for providing the antibodies against FABPpm and Dr Woldegiorgis for providing the antibodies against M-CPT-I.

\section{FUNDING}

This study was supported by the Netherlands Organisation for Health Research and Development [ZonMw grant number 912-04-075], the European Community [Integrated Project LSHM-CT-2004-005272, Exgenesis], the Natural Sciences and Engineering Research Council of Canada and the Heart and Stroke Foundation of Ontario. J.J.F.P.L. is the recipient of a VIDI innovational research grant from the Netherlands Organization for Scientific Research [grant number 016.036.305]. A. B. is the Canada Research Chair in Metabolism and Health. J.F.C.G. is the Netherlands Heart Foundation Professor of cardiac metabolism.

\section{REFERENCES}

1 Stanley, W. C., Recchia, F. A. and Lopaschuk, G. D. (2005) Myocardial substrate metabolism in the normal and failing heart. Physiol. Rev. 85, 1093-1129

2 Luiken, J. J., Turcotte, L. P. and Bonen, A. (1999) Protein-mediated palmitate uptake and expression of fatty acid transport proteins in heart giant vesicles. J. Lipid Res. $\mathbf{4 0}$, 1007-1016

3 Glatz, J. F., Bonen, A., Ouwens, D. M. and Luiken, J. J. (2006) Regulation of sarcolemmal transport of substrates in the healthy and diseased heart. Cardiovasc. Drugs Ther. $\mathbf{2 0}$, $471-476$

4 Luiken, J. J., Coort, S. L., Koonen, D. P., van der Horst, D. J., Bonen, A., Zorzano, A. and Glatz, J. F. (2004) Regulation of cardiac long-chain fatty acid and glucose uptake by translocation of substrate transporters. Pflugers Arch. 448, 1-15

5 Eaton, S. (2002) Control of mitochondrial beta-oxidation flux. Prog. Lipid. Res. 41, $197-239$

6 Kerner, J. and Hoppel, C. (2000) Fatty acid import into mitochondria. Biochim. Biophys. Acta 1486, 1-17

7 Weis, B. C., Cowan, A. T., Brown, N., Foster, D. W. and McGarry, J. D. (1994) Use of a selective inhibitor of liver carnitine palmitoyltransferase I (CPT I) allows quantification of its contribution to total CPT I activity in rat heart: evidence that the dominant cardiac CPT I isoform is identical to the skeletal muscle enzyme. J. Biol. Chem. 269, 26443-26448

8 Awan, M. M. and Saggerson, E. D. (1993) Malonyl-CoA metabolism in cardiac myocytes and its relevance to the control of fatty acid oxidation. Biochem. J. 295, 61-66

9 Saddik, M., Gamble, J., Witters, L. A. and Lopaschuk, G. D. (1993) Acetyl-CoA carboxylase regulation of fatty acid oxidation in the heart. J. Biol. Chem. $\mathbf{2 6 8}$ 25836-25845

10 Carley, A. N., Atkinson, L. L., Bonen, A., Harper, M. E., Kunnathu, S., Lopaschuk, G. D. and Severson, D. L. (2007) Mechanisms responsible for enhanced fatty acid utilization by perfused hearts from type 2 diabetic db/db mice. Arch. Physiol. Biochem. 113, $65-75$

11 Luiken, J. J., van Nieuwenhoven, F. A., America, G., van der Vusse, G. J. and Glatz, J. F. (1997) Uptake and metabolism of palmitate by isolated cardiac myocytes from adult rats: involvement of sarcolemmal proteins. J. Lipid. Res. 38, 745-758

12 Bonen, A., Han, X. X., Habets, D. D., Febbraio, M., Glatz, J. F. and Luiken, J. J. (2007) A null mutation in skeletal muscle FAT/CD36 reveals its essential role in insulin- and AICAR-stimulated fatty acid metabolism. Am. J. Physiol. Endocrinol. Metab. 292, E1740-E1749

13 Rupp, H., Wahl, R. and Hansen, M. (1992) Influence of diet and carnitine palmitoyltransferase I inhibition on myosin and sarcoplasmic reticulum. J. Appl. Physiol. 72, 352-360

14 Schmitz, F. J., Rosen, P. and Reinauer, H. (1995) Improvement of myocardial function and metabolism in diabetic rats by the carnitine palmitoyl transferase inhibitor etomoxir. Horm. Metab. Res. 27, 515-522

15 Hayashi, K., Okumura, K., Matsui, H., Murase, K., Kamiya, H., Saburi, Y., Numaguchi, Y., Toki, Y. and Hayakawa, T. (2001) Involvement of 1,2-diacylglycerol in improvement of heart function by etomoxir in diabetic rats. Life Sci. 68, 1515-1526

16 Cabrero, A., Merlos, M., Laguna, J. C. and Carrera, M. V. (2003) Down-regulation of acyl-CoA oxidase gene expression and increased NF- $\kappa$ B activity in etomoxir-induced cardiac hypertrophy. J. Lipid Res. 44, 388-398

17 Campbell, S. E., Tandon, N. N., Woldegiorgis, G., Luiken, J. J., Glatz, J. F. and Bonen, A. (2004) A novel function for fatty acid translocase (FAT)/CD36: involvement in long chain fatty acid transfer into the mitochondria. J. Biol. Chem. 279, 36235-36241

18 Scholte, H. R., Jennekens, F. G. and Bouvy, J. J. (1979) Carnitine palmitoyltransferase II deficiency with normal carnitine palmitoyltransferase I in skeletal muscle and leucocytes. J. Neurol. Sci. 40, 39-51

19 Hasselbaink, D. M., Roemen, T. H. and van der Vusse, G. J. (2002) Protein acylation in the cardiac muscle like cell line, H9c2. Mol. Cell. Biochem. 239, 101-112

20 Yotsumoto, T., Naitoh, T., Kitahara, M. and Tsuruzoe, N. (2000) Effects of carnitine palmitoyltransferase I inhibitors on hepatic hypertrophy. Eur. J. Pharmacol. 398, 297-302

21 Koonen, D. P., Coumans, W. A., Arumugam, Y., Bonen, A., Glatz, J. F. and Luiken, J. J. (2002) Giant membrane vesicles as a model to study cellular substrate uptake dissected from metabolism. Mol. Cell. Biochem. 239, 121-130

22 Kammermeier, H. and Rose, H. (1988) Are isolated cardiomyocytes a suitable experimental model in all lines of investigation in basic cardiology? Basic Res. Cardiol. 83, 343-349

23 Arieli, R., Ben-Haim, S. A., Hayam, G. and Edoute, Y. (1992) Heart energetic efficiency in $\mathrm{O}_{2}$-exposed rats studied in isolated working heart. J. Appl. Physiol. 73, 2289-2296

24 Ylitalo, K., Ala-Rami, A., Vuorinen, K., Peuhkurinen, K., Lepojarvi, M., Kaukoranta, P., Kiviluoma, K. and Hassinen, I. (2001) Reversible ischemic inhibition of $F_{1} F_{0}$-ATPase in rat and human myocardium. Biochim. Biophys. Acta 1504, 329-339

25 Randle, P. J., Garland, P. B., Newsholme, E. A. and Hales, C. N. (1965) The glucose fatty acid cycle in obesity and maturity onset diabetes mellitus. Ann. N.Y. Acad. Sci. 131, 324-333 
26 Bartlett, K. and Eaton, S. (2004) Mitochondrial $\beta$-oxidation. Eur. J. Biochem. 271, 462-469

27 Westerhoff, H. V., Groen, A. K. and Wanders, R. J. (1984) Modern theories of metabolic control and their applications (review). Biosci. Rep. 4, 1-22

28 Vetter, R. and Rupp, H. (1994) CPT-1 inhibition by etomoxir has a chamber-related action on cardiac sarcoplasmic reticulum and isomyosins. Am. J. Physiol. 267, H2091-H2099

29 Kato, K., Chapman, D. C., Rupp, H., Lukas, A. and Dhalla, N. S. (1999) Alterations of heart function and $\mathrm{Na}^{+}-\mathrm{K}^{+}$-ATPase activity by etomoxir in diabetic rats. J. Appl. Physiol. 86. 812-818

30 Dhalla, N. S., Elimban, V. and Rupp, H. (1992) Paradoxical role of lipid metabolism in heart function and dysfunction. Mol. Cell. Biochem. 116, 3-9

31 Zarain-Herzberg, A. and Rupp, H. (2002) Therapeutic potential of CPT I inhibitors: cardiac gene transcription as a target. Expert Opin. Investig. Drugs. 11, 345-356

32 Stanley, W. C., Lopaschuk, G. D. and McCormack, J. G. (1997) Regulation of energy substrate metabolism in the diabetic heart. Cardiovasc. Res. 34, 25-33

Received 30 October 2008/17 December 2008; accepted 13 January 2009

Published as BJ Immediate Publication 13 January 2009, doi:10.1042/BJ20082159
33 Coort, S. L., Hasselbaink, D. M., Koonen, D. P., Willems, J., Coumans, W. A., Chabowski, A., van der Vusse, G. J., Bonen, A., Glatz, J. F. and Luiken, J. J. (2004) Enhanced sarcolemmal FAT/CD36 content and triacylglycerol storage in cardiac myocytes from obese zucker rats. Diabetes $\mathbf{5 3}, 1655-1663$

34 Carley, A. N. and Severson, D. L. (2005) Fatty acid metabolism is enhanced in type 2 diabetic hearts. Biochim. Biophys. Acta 1734, 112-126

35 Lopaschuk, G. D. (2006) Optimizing cardiac fatty acid and glucose metabolism as an approach to treating heart failure. Semin. Cardiothorac. Vasc. Anesth. 10, 228-230

36 Rajabi, M., Kassiotis, C., Razeghi, P. and Taegtmeyer, H. (2007) Return to the fetal gene program protects the stressed heart: a strong hypothesis. Heart Fail. Rev. 12, 331-343

37 Kampf, J. P. and Kleinfeld, A. M. (2007) Is membrane transport of FFA mediated by lipid, protein, or both? An unknown protein mediates free fatty acid transport across the adipocyte plasma membrane. Physiology (Bethesda) 22, 7-14

38 Habets, D. D., Coumans, W. A., Voshol, P. J., den Boer, M. A., Febbraio, M., Bonen, A. Glatz, J. F. and Luiken, J. J. (2007) AMPK-mediated increase in myocardial long-chain fatty acid uptake critically depends on sarcolemmal CD36. Biochem. Biophys. Res. Commun. 355, 204-210 